\title{
Susceptibilidad cutánea a la infección por SARS-CoV-2 según la expresión de los factores de entrada viral en la piel
}

\author{
Myriam Garduño-Soto ${ }^{*}$ y José A. Choreño-Parra²
}

${ }^{1}$ Secretaría de Salud, Hospital General de México "Dr. Eduardo Liceaga", Departamento de Dermatología; ${ }^{2}$ Instituto Politécnico Nacional, Escuela Nacional de Ciencias Biológicas. Ciudad de México, México

\section{Resumen}

Introducción: Reportes de manifestaciones dermatológicas en pacientes con COVID-19 sugieren un posible tropismo cutáneo del virus SARS-CoV-2; sin embargo, se desconoce la capacidad de este virus para infectar la piel. Objetivo: Determinar la susceptibilidad de la piel a la infección por SARS-CoV-2 con base en la expresión de los factores de entrada viral ACE2 y TMPRSS2 en dicho órgano. Método: Se buscaron los genes ACE2 y TMPRSS2 en la piel, para lo cual se realizó un análisis extenso de las bases de datos de expresión genética en tejidos humanos. Asimismo, se evaluó la expresión de dichos genes en líneas celulares humanas derivadas de la piel. Resultados: Los análisis mostraron alta expresión conjunta de ACE2 y TMPRSS2 en el tracto gastrointestinal y en los riñones, pero no en la piel. Solo la línea celular de queratinocitos humanos inmortalizados HaCaT expresó niveles detectables de ACE2 y ninguna línea celular de origen cutáneo expresó TMPRSS2. Conclusiones: Los resultados sugieren que las manifestaciones dermatológicas en pacientes con COVID-19 no pueden ser atribuidas directamente al virus; es posible que sean originadas por el daño endotelial a los vasos sanguíneos cutáneos y el efecto de los mediadores inflamatorios circulantes producidos en respuesta al virus.

PALABRAS CLAVE: SARS-CoV-2. COVID-19. Infecciones virales de la piel. Manifestaciones cutáneas de COVID-19. ACE2.

\section{Cutaneous susceptibility to SARS-CoV-2 infection according to the expression of viral entry factors in the skin}

\begin{abstract}
Introduction: Reports of dermatological manifestations in patients with COVID-19 suggest a possible cutaneous tropism of SARS-CoV-2; however, the capacity of this virus to infect the skin is unknown. Objective: To determine the susceptibility of the skin to SARS-CoV-2 infection based on the expression of viral entry factors ACE2 and TMPRSS2 in this organ. Method: A comprehensive analysis of human tissue gene expression databases was carried out looking for the presence of the ACE2 and TMPRSS2 genes in the skin. mRNA expression of these genes in skin-derived human cell lines was also assessed. Results: The analyses showed high co-expression of ACE2 and TMPRSS2 in the gastrointestinal tract and kidney, but not in the skin. Only the human immortalized keratinocyte HaCaT cell line expressed detectable levels of ACE2, and no cell line originating in the skin expressed TMPRSS2. Conclusions: Our results suggest that cutaneous manifestations in patients with COVID-19 cannot be directly attributed to the virus. It is possible that cutaneous blood vessels endothelial damage, as well as the effect of circulating inflammatory mediators produced in response to the virus, are the cause of skin involvement.
\end{abstract}

KEY WORDS: SARS-CoV-2. COVID-19. Viral skin infections. COVID-19 cutaneous manifestations. ACE2.

Correspondencia:

*Myriam Garduño-Soto

E-mail: myriam_gardst@outlook.com
Gac Med Mex. 2020;156:354-357

Disponible en PubMed

www.gacetamedicademexico.com

0016-3813/@ 2020 Academia Nacional de Medicina de México, A.C. Publicado por Permanyer. Este es un artículo open access bajo la licencia CC BY-NC-ND (http://creativecommons.org/licenses/by-nc-nd/4.0/). 


\section{Introducción}

La aparición del nuevo coronavirus asociado al síndrome respiratorio agudo severo 2 (SARS-CoV-2) constituye una emergencia de salud pública de importancia internacional. Al 19 de mayo de 2020, la infección humana producida con este virus, denominada enfermedad por coronavirus 2019 (COVID-19) había causado más de 4.5 millones de casos y 310000 muertes en todo el mundo. ${ }^{1}$ Aun cuando el virus afecta principalmente a los pulmones, ${ }^{2,3}$ estudios recientes han reportado manifestaciones dermatológicas en pacientes con COVID-19.4,5 Estos hallazgos podrían estar relacionados con un posible tropismo cutáneo del virus, sin embargo, se desconoce la capacidad de SARS-CoV-2 para infectar la piel.

El riesgo de un órgano o tejido humano específico de infección por SARS-CoV-2 está determinado por la presencia de la enzima convertidora de angiotensina 2 (ACE2) en sus células locales, la cual es reconocida por la proteína espiga (S) del virus. ${ }^{6}$ Además, la activación de la proteína $S$ por parte de la proteasa de serina transmembranal 2 (TMPRSS2) del huésped es crucial para que esta proteína lleve a cabo la fusión de membranas virales y celulares. ${ }^{6}$ De esta forma, el tropismo de SARS-CoV-2 se encuentra determinado por la distribución de ACE2 y TMPRSS2 en los tejidos humanos. Actualmente, existe poca información sobre la expresión de estos factores de entrada viral en la piel. Por ese motivo, se realizó un análisis sistemático de las bases de datos públicas de expresión génica de tejidos humanos en busca de la presencia de los genes ACE2 y TMPRSS2 en la piel.

\section{Método}

Se recuperaron los valores absolutos de la expresión relativa de los genes ACE2 y TMPRSS2 de la base de datos GeneAtlas U133A, gcrma incluida en el portal BioGPS (http://biogps.org). Esta base de datos incluye el patrón de expresión de mARN de 79 tejidos humanos, para el cual se utilizaron los microarreglos de oligonucleótidos de alta densidad U133 de Affymetrix. Se construyeron mapas de calor para representar la expresión de los genes evaluados mediante valores de expresión relativa en términos de unidades de hibridación para las sondas 222257_s_at en ACE2, y 211689_s_at en TMPRSS2. Las unidades de hibridación de las células T se utilizaron para establecer un valor de corte superior al cual la expresión de ambos genes se considera detectable y superior al nivel de hibridación basal.

También se recuperó el valor normalizado de la expresión de ARN (NX) en ACE2 (ENSG00000130234) y TMPRSS2 (ENSG00000184012) de la base de datos Human Protein Atlas (HPA, http://www.proteinatlas. org), la cual incluye datos transcriptómicos de tres proyectos de secuenciación (HPA, GTEx y FANTOM5), generados por secuenciación de ARN (RNA-Seq) en 37 tejidos humanos, 18 tipos de células sanguíneas y 64 líneas celulares. ${ }^{7,8}$ El NX para cada gen en cada órgano, tejido y línea celular se definió como el valor máximo en las tres fuentes de datos. Los gradientes de color se construyeron a partir de los NX de ACE2 y TMPRSS2, con corte en un NX como límite para la detección de los genes en todos los tejidos o tipos celulares. Los niveles de ACE2 y TMPRSS2 en términos de expresión en forma de proteína en diferentes tejidos se recolectaron del HPA. Estos datos se obtienen mediante inmunohistoquímica y se presentan con intensidad de la tinción, de acuerdo con la observación directa de un evaluador, según la fracción de células positivas para cada proteína en cada tejido (baja, < $25 \%$; media, 25 a $75 \%$; alta > $75 \%$ ).

\section{Resultados}

El análisis de los patrones de expresión tisular de los genes ACE2 y TMPRSS2 en la base de datos BioGPS mostró una alta coexpresión de ACE2 y TMPRSS2 en el intestino delgado y el riñón, pero no en la piel (Figura 1a).

Para corroborar estos hallazgos, se obtuvo el NX de los genes ACE2 y TMPRSS2 en los tejidos registrado en el HPA. Dado que esta base de datos se basa en la RNA-seq, su análisis puede producir resultados más específicos y sensibles. El análisis de datos confirmó la coexpresión de ACE2 y TMPRSS2 en el intestino delgado y el riñón, así como en el duodeno, vesícula biliar y colon, pero no en la piel (Figura 1b). Como los valores generales de expresión de ARN de un órgano pueden no reflejar la expresión génica entre los subconjuntos celulares locales, también se analizó la expresión de ACE2 y TMPRSS2 en las líneas celulares incluidas en el HPA, algunas de las cuales tienen su origen en la piel. A partir de este análisis se identificó que solo la línea celular HaCaT de queratinocitos inmortalizados humanos expresó niveles detectables de ACE2, así como algunas líneas celulares originadas a partir de otros tejidos (Figura 1c); sin embargo, ninguna de origen cutáneo expresó TMPRSS2. EL HPA también 

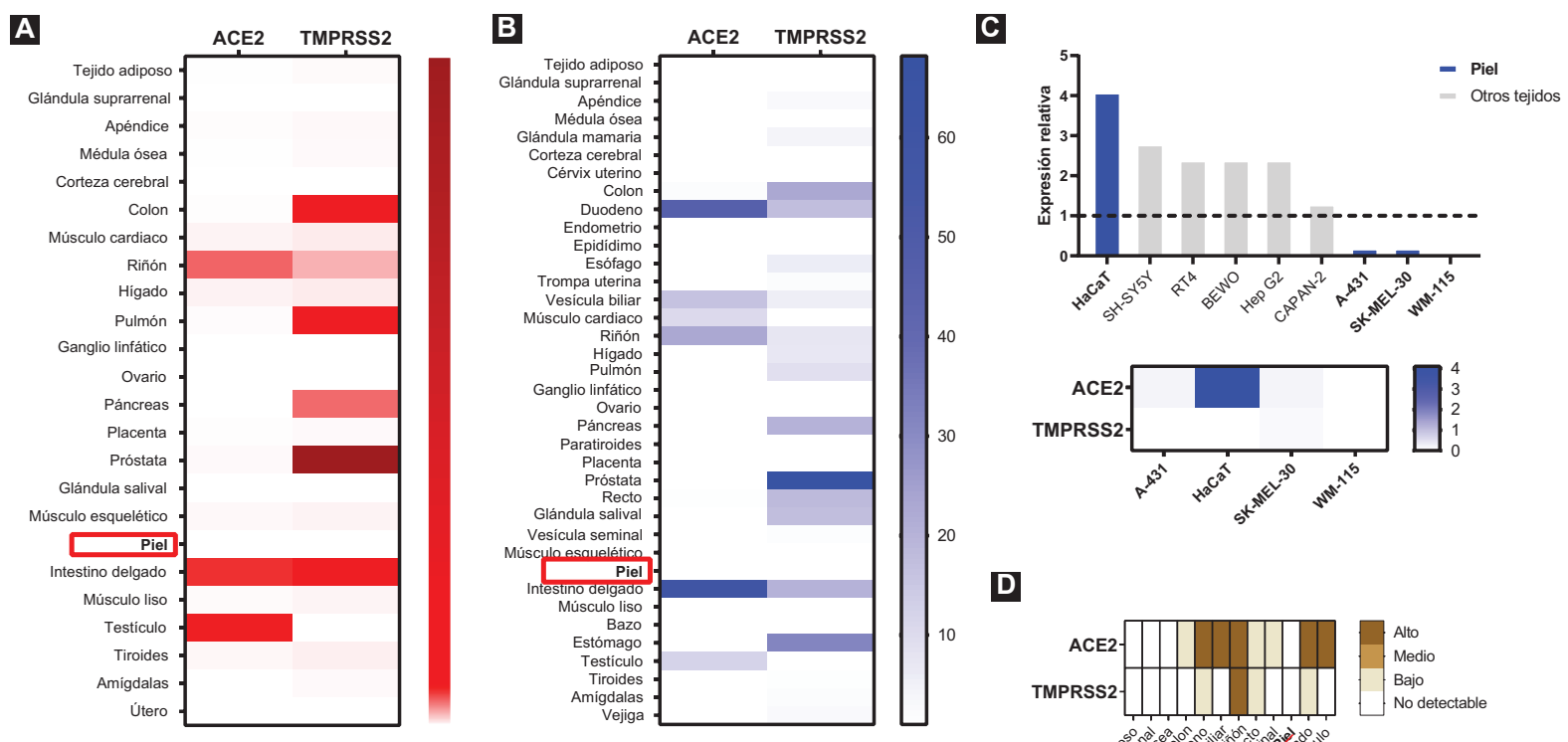

D

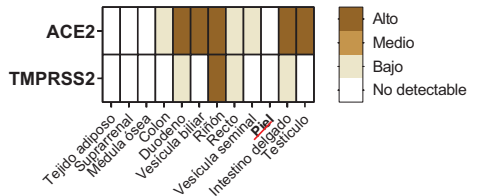

Figura 1. ACE2 y TMPRSS2 no se expresan en la piel humana. A) Patrones de expresión tisular de ACE2 y TMPRSS2 en la base de datos GeneAtlas U133A gcrma, disponible a en BioGPS (http://biogps.org). El gradiente de color se construyó utilizando valores de expresión relativa en términos de unidades de hibridación para las sondas 222257_s_at en ACE2 y 211689_s_at en TMPRSS2. Las unidades de hibridación de las células $T$ se utilizaron para establecer un valor de corte para la expresión detectable de ambos genes superior al nivel de hibridación de fondo. B) Los valores normalizados de expresión de ARN (NX) para los genes ACE2 (ENSG00000130234) y TMPRSS2 (ENSG00000184012) se recuperaron de la base de datos Human Protein Atlas (http://www.proteinatlas.org). EI NX para cada gen en cada órgano o tejido representa el valor máximo de NX en las tres fuentes de datos. El gradiente del mapa de color de calor se construyó utilizando los NX de ACE2 y TMPRSS2, con corte de un NX como límite para la detección en todos los tejidos o tipos de células. C) NX para ACE2 y TMPRSS2 en varias líneas celulares humanas. Los NX de las líneas celulares con origen en la piel se muestran en barras azules. D) Los niveles de las proteínas ACE2 y TMPRSS2 en diferentes tejidos se recuperaron de la base de datos de HPA. Estos datos se obtuvieron por inmunohistoquímicas y se presentan con la intensidad de la tinción, basada en la anotación manual según la fracción de células positivas a cada proteína observada en cada tejido (baja, < 25 \%; media, 25 a 75 \%; alta, > 75 \%).

incluye información de los niveles de proteínas tisulares obtenidos por inmunohistoquímica. Conforme a esos datos, se identificó que los patrones tisulares de la expresión de las proteínas ACE2 y TMPRSS2 fueron consistentes con los datos de expresión de ARN, lo que mostró la ausencia de factores de entrada viral en diferentes subtipos celulares de la piel (Figura 1d).

\section{Discusión}

Los resultados del análisis indican que, al menos en condiciones homeostáticas, la piel sana no puede ser infectada directamente por SARS-CoV-2; por lo tanto, las manifestaciones dermatológicas en pacientes con COVID-19 pueden tener un origen indirecto. Los posibles mecanismos de las lesiones cutáneas durante la infección por SARS-CoV-2 incluyen la propagación del virus desde los tejidos adyacentes. En este sentido, la expresión de ACE2 se ha encontrado en el endotelio de varios tejidos ${ }^{9}$ y evidencia reciente demuestra que SARS-CoV-2 puede infectar las células endoteliales..$^{10}$ Del mismo modo, informes previos de expresión de
ACE2 en las capas basales de epidermis y en los folículos pilosos ${ }^{9,11}$ mostraron que este receptor se puede detectar principalmente en vasos capilares cutáneos, pero no en células de la piel. Por lo tanto, es posible que SARS-CoV-2 repercuta en la piel debido a la contigüidad de las células cutáneas con el endotelio de los vasos sanguíneos locales.

La afectación del endotelio también podría resultar en disfunción endotelial, microtrombosis e hipoxia en diferentes órganos, incluyendo la piel. De hecho, las lesiones cutáneas en pacientes con infección por SARS-CoV-2, como livedo reticularis, sabañones y necrosis de dedos de las manos y pies, están relacionadas con hipoxia en la piel. ${ }^{5} \mathrm{La}$ infección endotelial y los altos niveles circulantes de citocinas inflamatorias también podrían causar vasodilatación y edema en la piel, lo que explica la erupción eritematosa, urticaria y erupciones maculopapulares en algunos pacientes con COVID-19. ${ }^{4}$ Finalmente, un estudio reciente muestra que el interferón gamma puede incrementar la expresión de ACE2 en células epiteliales pulmonares. ${ }^{12}$ Por lo tanto, es posible que la expresión cutánea de ACE2 
y TMPRSS2 también pueda ser promovida por mediadores inflamatorios circulantes producidos en respuesta a la infección, lo que incrementa la capacidad de SARS-CoV-2 para infectar la piel.

\section{Conclusiones}

Las manifestaciones dermatológicas de COVID-19 no pueden atribuirse a un efecto directo mediado por el virus, ya que SARS-CoV-2 no puede infectar la piel sana. Sin embargo, estudios futuros deben evaluar la posibilidad de que la expresión de ACE2 en las células de la piel pueda ser regulada por mediadores inflamatorios circulantes producidos en respuesta al virus, así como en pacientes con condiciones dermatológicas crónicas autoinmunes e inflamatorias.

\section{Conflicto de intereses}

Los autores declaran que la investigación se llevó a cabo en ausencia de cualquier relación comercial o financiera que pudiera interpretarse como un posible conflicto de intereses.

\section{Financiación}

Esta investigación no recibió financiamiento.

\section{Responsabilidades éticas}

Protección de personas y animales. Los autores declaran que no se realizaron experimentos en humanos o animales para este estudio.
Confidencialidad de los datos. Los autores declaran que han seguido los protocolos de su centro de trabajo sobre la publicación de datos de pacientes.

Derecho a la privacidad y consentimiento informado. Los autores declaran que no aparecen datos de pacientes en este artículo.

\section{Bibliografía}

1. World Health Organization [Internet]. Suiza: Coronavirus disease (COVID-2019) situation reports. Situation report - 119; 2020.

2. Huang $C$, Wang $Y$, Li X, Ren L, Zhao J, Hu Y et al. Clinical features of patients infected with 2019 novel coronavirus in Wuhan, China. Lancet. 2020;395:497-506.

3. Richardson S, Hirsch JS, Narasimhan M, Crawford JM, McGinn T, Davidson KW, et al. Presenting characteristics, comorbidities, and outcomes among 5700 patients hospitalized with COVID-19 in the New York City area. JAMA 2020;323:2052-2059.

4. Recalcati S. Cutaneous manifestations in COVID-19: a first perspective. J Eur Acad Dermatol Venereol. 2020;34.

5. Galván-Casas C, Català A, Carretero-Hernández G, Rodríguez-Jiménez P, Fernández-Nieto D, Rodríguez-Villa Lario A, et al. Classification of the cutaneous manifestations of COVID-19: a rapid prospective nationwide consensus study in Spain with 375 cases. Br J Dermatol. 2020.

6. Hoffmann M, Kleine-Weber H, Schroeder S, Kruger N, Herrler T, Erichsen S, et al. SARS-CoV-2 cell entry depends on ACE2 and TMPRSS2 and is blocked by a clinically proven protease inhibitor. Cell. 2020;181:271-280.

7. Yu NY, Hallström BM, Fagerberg L, Ponten F, Kawaji H, Carninci $P$, et al. Complementing tissue characterization by integrating transcriptome profiling from the Human Protein Atlas and from the FANTOM5 consortium. Nucleic Acids Res. 2015;43:6787-6798.

8. Keen JC, Moore HM. The Genotype-Tissue Expression (GTEx) project: Linking clinical data with molecular analysis to advance personalized medicine. J Pers Med. 2015;5;22-29.

9. Hamming I, Timens W, Bulthuis ML, Lely AT, Navis G, van Goor H Tissue distribution of ACE2 protein, the functional receptor for SARS coronavirus. A first step in understanding SARS pathogenesis. J Pathol. 2004;203:631-637.

10. Varga Z, Flammer AJ, Steiger P, Haberecker M, Andermatt R, Zinkernagel AS, et al. Endothelial cell infection and endotheliitis in COVID-19. Lancet. 2020;395:1417-1418.

11. Grzegrzolka J, Swiatko K, Pula B, Zamirska A, Olbromski M, Bieniek A, et al. ACE and ACE2 expression in normal and malignant skin lesions. Folia Histochem Cytobiol. 2013;51;232-238.

12. Ziegler CGK, Allon SJ, Nyquist SK, Mbano IM, Miao VN, Tzouanas CN, et al. SARS-CoV-2 receptor ACE2 is an interferon-stimulated gene in human airway epithelial cells and is detected in specific cell subsets across tissues. Cell. 2020;181:1016-1035. 